Proceedings of Anticancer Research

Review Article

\title{
Exploring the Management of Stem Cell Research Based on Bioethics
}

\author{
Yanming Jiang
}

Zhongke Ju Yan Stem Cell Co., No 132013, south side of 2nd floor, Block E of the Business Park, Hi-

Tech Industrial Development Zone, Jilin City, Jilin Province, China

\begin{abstract}
Stem cell research has brought hope to mankind to overcome various diseases, but ethical issues arise in stem cell research, and people have doubts about how to develop stem cell research healthily and whether it can bring the gospel to mankind. Management of stem cell research based on bioethics is extremely necessary. From the perspective of bioethics, the number of research literature is used to analyze the development of stem cell research and the management of stem cell research in China, to provide suggestions for further strengthening the management of stem cell research.
\end{abstract}

Keywords: Bioethics; Stem cells; Research management

Publication date: September, 2020

Publication online: 30 September, 2020

*Corresponding author: Yanming Jiang, zkjygxb@163. com

It is believed that biology will shine in the twentyfirst century, and stem cell research has always been an important area in the scientific community. Stem cells harvested from bone marrow or embryos can be grown to produce all organs and tissues of the human body, which can bring a healthy and stable source of human organs for transplantation, with the hope of tackling major diseases such as cardiovascular disease and cancer. The application of stem cells has entered the clinical era, and therapies such as hematopoietic stem cells and bone marrow transplantation have been promoted. Stem cell research is advancing at a rapid pace, and its applications continue to be significant to human health and life. The continuing advancement and applications of stem cell research have increased its ability to treat or prevent diseases. However, stem cell research has been regarded as a "double-edged sword" since its inception. If stem cell research is not properly and effectively managed, it will easily go astray and violate human values and dignity.

\section{A Bioethical Perspective on Stem Cell Research}

The basis for the management of stem cell research is bioethics. Bioethics began in the middle of the last century and has gradually become an independent discipline, which has nearly 40 years of independent research history in China. The scope of its discipline has been deepening with the rapid development of stem cell research, which has expanded from mental health research and doctor-patient relationship research to current stem cell research management, hospice care, genetically modified foods, and other new topics that have emerged with the development of technology ${ }^{[1]}$. In particular, it is more controversial and difficult to conduct bioethical research and management of stem cell research activities due to its unique characteristics of stem cell research.

The Bioethics framework is based on the principles of autonomy, beneficence, justice, and non-harm, and bioethical issues should be addressed based on this ideological principle. However, because people are in different cultural contexts, their views and implementation of bioethics vary considerably ${ }^{[2]}$.

The debate in the bioethical context of embryonic stem cell research is whether people identify early embryos as human beings. Some people oppose stem cell research because of the belief that embryos are people too, and experimenting with them and discarding them would be tantamount to murder ${ }^{[3]}$. Some argue that early embryos do not have human senses and 
Figure 1. Stem cell classification and characteristic

\begin{tabular}{|c|c|c|}
\hline Classification method & Name & Characteristic \\
\hline \multirow{2}{*}{ Developmental Stages of Stem Cells } & Embryonic stem cell & $\begin{array}{l}\text { A highly undifferentiated cell that is pluripotent and can differentiate to } \\
\text { all tissues and organs of an adult animal, including germ cells }\end{array}$ \\
\hline & Somatic stem cell & $\begin{array}{l}\text { Many tissues and organs of adult animals have the ability to repair and } \\
\text { regenerate }\end{array}$ \\
\hline \multirow{3}{*}{ Developmental potential of stem cells } & Totipotent stem cell & $\begin{array}{l}\text { Similar morphological characteristics and strong differentiation ability to } \\
\text { early embryonic cells, which can proliferate indefinitely and differentiate } \\
\text { into more than } 200 \text { cell types throughout the body }\end{array}$ \\
\hline & Pluripotent stem cell & $\begin{array}{l}\text { Having the potential to differentiate into multiple tissue cells, but } \\
\text { losing the ability to develop into a complete individual with a limited } \\
\text { developmental potential; bone marrow pluripotent hematopoietic stem } \\
\text { cells are a typical example }\end{array}$ \\
\hline & Monopotent stem cell & Only differentiating to one type or two closely related types of cells \\
\hline
\end{tabular}

consciousness, so they are not people. There are levels of respect for embryos and they should not be equated with respect for real people.

\section{Status of stem cell research and management in China}

China promulgated the Administrative Measures for Stem Cell Clinical Research (Trial) in 2015, in an attempt to regulate stem cell clinical research, ensuring that research institutions are qualified, prohibit relevant advertisements, and protect the privacy and rights of subjects. China's current stem cell research has been successfully supported by national science and technology planning priorities. The amount of research literature of stem cells in China is now approaching the amount of literature in the United States, as shown in Figure 2.

Figure 2. The number of stem cell research literature in China in recent years

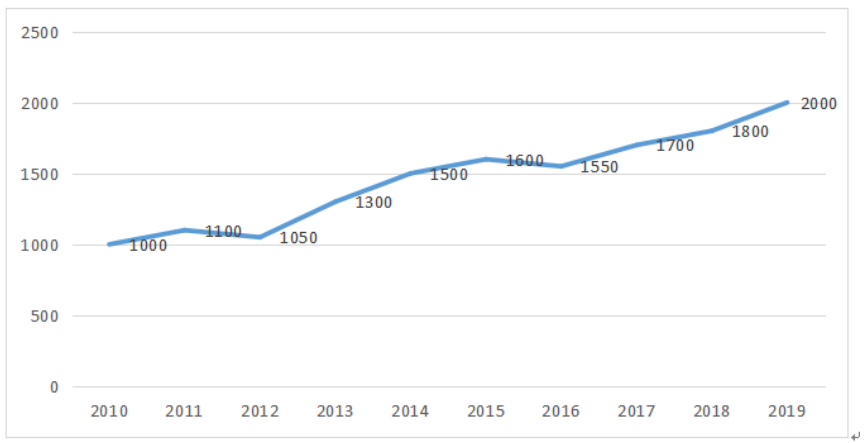

Stem cell research is booming, and so is the study of its ethics. Stem cell research has advanced by leaps and bounds in recent years, and topics such as chimeric embryos, reproductive cloning, and genetic modification come to the forefront and spark numerous ethical debates. In China, the number of papers devoted to stem cell research and ethics research is shown in Figure 3.

Figure 3. The number of Literature in Stem Cell Research and Ethical Research

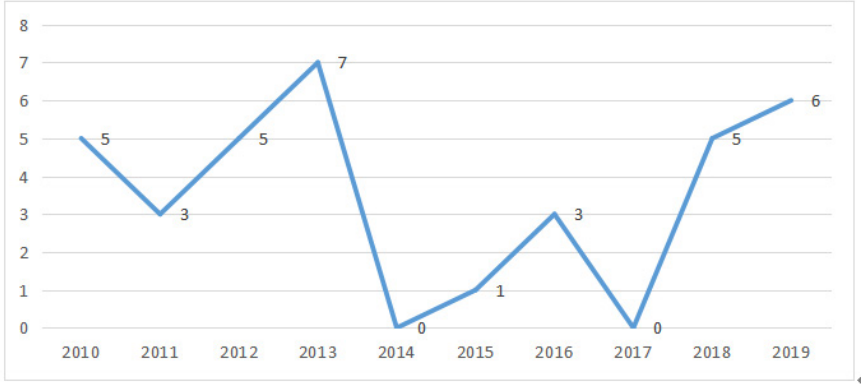

It is evident that there is more discussion on bioethics related to stem cell research in China, but there is not much research literature. In some early-starting countries, research is more advanced. And stem cell research is more accepted in our population, believing that human life begins at birth, so there is not much debate about whether embryos are involved in human rights. In 2019, a survey on the cognitive and ethical discussion of stem cell research from a total of 10 hospitals in Shanghai and Beijing, $80 \%$ of respondents supported stem cell research, but more than $90 \%$ of health care professionals believed that stem cell research, especially clinical research, must address management issues, standardize the access system, and improve relevant laws and regulations ${ }^{[4]}$.

At present, many medical institutions in China are extremely pursuing profit by using the name of stem cell research. Many institutions exaggerate the therapeutic efficacy under the name of stem cell therapy, claiming that they can treat difficult diseases that the medical community has not given definitive research results, to deceive patients' trust and gain financial benefits ${ }^{[5]}$. At present, there are still some hidden dangers in 
the standard of stem cell research, and there are still some institutions that conduct illegal research and escape supervision. At present, China is relatively mature in terms of blood stem cell technology, so stem cell research can be used to treat blood diseases, but stem cell research has not been approved to treat any other kinds of diseases and it has a limited scope of research. Current stem cell research lags behind the clinical treatment, and its scope of application has been expanded in violation of the law. Nevertheless, it is still hoped that stem cell research will continue to advance and technological innovation will occur, so that this technology can be used to overcome various diseases and become an effective treatment alternative to medication and surgery, subverting traditional treatments and gaining in-depth development and application. This requires enhanced management of stem cell research guided by the theory of bioethics to advance stem cell research on the right path ${ }^{[6]}$.

\section{Recommendations for the management of stem cell research based on bioethics}

\subsection{Establishment of sickness ethics committees}

Government support is extremely important for stem cell research in China. Under the leadership of the government, a bioethics committee has been established and the management system of the committee has been continuously improved according to the situation in China, to strictly regulate the entire stem cell research and application field. In foreign countries, bioethics committees change frequently, but the institutions are formed by the government, which provides strong support to enable the committees to exercise their authority and obtain the support of experts in the field, as well as the assistance of various social institutions, which strengthens the research and regulatory power ${ }^{[7]}$. The Bioethics Committee has a good system of disclosure of management information, regardless of whether there is a change in membership so that it is possible to have a comprehensive view of the work being done, to draw lessons from the past, and to carry out its work expeditiously. China can learn from the experience of foreign countries in establishing bioethics committees, establish and improve relevant institutions in China, promote theoretical research in bioethics, give reference opinions on the path and direction of development of stem cell research, and regulate stem cell research and application fields from the perspective of bioethics after authoritative investigation and research. Government departments grasp the situation of stem cell research and application through bioethics committees and make policy support or regulatory initiatives. The bioethics committee should do the construction of information and the construction of the open information platform. The sharing platform should be completed and put into use as soon as possible ${ }^{[8]}$.

\subsection{Establishing and improving relevant laws and regulations}

In 2018, there were instances in China where a genetic compilation of fetuses was done illegally. While children have human and reproductive rights, the impact of genetic compilation on them or even humanity is incalculable. The researchers who performed the relevant operations were punished by law, but the fetus was already born and the consequences were unthinkable. Rather than dealing with the results of the illegal research after it has occurred, it is better to control it at the source and avoid the occurrence of illegal clinical applications through the formulation and improvement of relevant laws and regulations. Under the condition of information disclosure and full discussion, modern management of stem cell research should be conducted and relevant laws and regulations established and improved in line with the basic standard of bioethical norms, to enable people to move forward on the path of health and happiness and promote stem cell research and application in the right direction ${ }^{[9]}$. Taking into account the current experience of other countries and our situation, the views of stem cell research on bioethics are the same. To vigorously develop stem cell research, we should not only increase investment in research but also quickly establish and improve laws and regulations that follow bioethics theory and meet the needs of the discipline. The development of the stem cell research field is changing rapidly, so the formulation of relevant laws and regulations should not remain unchanged for many years but should follow the development of the discipline of research and constantly innovate, so that the laws and regulations can be adapted to the needs of the discipline, rather than becoming an obstacle to the development of the discipline.

\subsection{Strengthening the review and monitoring process}

For stem cell research, a comprehensive ethical review system and oversight process should be established, continuously improved to make the system process more rigorous, to ensure coordination and cooperation between oversight bodies. Stem cell research in China has developed vigorously in recent years and has made 
certain achievements. However, there are some cases in which stem cell research has been conducted on the margins of unethical practices in the absence of a comprehensive ethical review system. At present, the benefits of stem cell research for therapeutic cloning have not been confirmed, and many research activities can be carried out using adult stem cells without the need to use human embryos for testing and without damaging them. In China, there are certain laws and regulations to regulate stem cell research, but there is no special responsible organization to supervise and review stem cell research. In the light of China's national conditions, we can make full use of the existing scientific research review and supervision departments to play a supervisory role.

Adding specialized agencies or adding work to the existing structure should be supervised and reviewed in stem cell research based on bioethical norms, to continuously improve the relevant processes, make the monitoring process more rigorous, put ethical review before stem cell research, and end violations at the source so that the research is conducted following the $\operatorname{law}^{[10]}$.

\subsection{Participation in international exchanges}

In terms of bioethics research, we should actively integrate into international research work, participate in international exchanges, and improve the level of bioethics research in China, to promote the development of stem cell research, improve the management level, and keep stem cell research on the right track. The current bioethics research in China is not active enough to promote policies, laws, and regulations related to stem cell research, and is lagging. Take the discussions at various international conferences as an opportunity to promote the forward development of bioethics in China, raise the importance of life, and improve the standard of bioethics research. We will provide support for stem cell research with the support of bioethics theory.

\section{Conclusion}

China now has laws and regulations related to stem cell research, so stem cell research before clinical application must be sure that the application is safe and effective, meet the requirements of bioethical review, subjects are informed, and voluntary participation in the trial, which help to protect the subjects and researchers of stem cell research. Government departments should increase their investment in bioethics research, raise the importance of stem cell research, and continuously improve the level of stem cell research based on China's conditions.

\section{References}

[1] Lin Y, Ma CG, Wang JP, et al. A survey on the perception of stem cell clinical research ethical issues among public hospital personnel in China[J]. Medicine and Philosophy, 2019, 40(19): 32-34.

[2] Wang JP, Bai LH, Ma CG, et al. Status of stem cell clinical research and its related ethics committees in public hospitals in China[J]. Chinese Medical Ethics, 2019, 32(1): 22-25.

[3] Du Y, Lu SP. The National Stem Cell Clinical Research Expert Committee held a meeting to review the project filing materials[J]. China Medicine Biotechnology, 2018, 13(6): 538.

[4] Li HL, Li J, Lin HL. Nursing safety management pitfalls and countermeasures in hematopoietic stem cell transplantation laminar flow wards[J]. Jilin Medicine, 2020, 41(6): 15201522.

[5] Yu HS, Chen WZ, Wang Y, et al. Effect of low-intensity pulsed ultrasound on the proliferation of cultured bone marrow-derived mesenchymal stem cells in vitro Support info[J]. Journal of China Medical University, 2011, 40(11): 971-974.

[6] Zhang CD. LDA and HMM-based text topic evolution model and its application[J]. 2014.

[7] Cui WS, Zhe J, Gong YQ, et al. Study on the safety and efficacy of absorbable cell scaffolds implanted with autologous adipose stem cells for penile subcutaneous tissue regeneration[J]. 2011.

[8] Li ZF, Wang Y, Zhao RZ, et al. Bone marrow mesenchymal stem cell-derived exosomes regulate the proliferation of myocardial microvascular endothelial cells[J]. Journal of the Third Military Medical University, 2019, 41(23): 2313-2321.

[9] Wu D, Zhang W, Liu YL, et al. The relationship between TLR4 and acute GVHD after hemispheric hematopoietic stem cell transplantation in mice[J]. Journal of Nanjing Medical University, 2013, 33(4): 462-466.

[10]Chen X, Ma HX, Li D, et al. Differentiation of human bone marrow-derived mesenchymal stem cells into hematopoietic cells in vivo[J]. Chinese Journal of Experimental Diagnostics, 2012(11): 27-29. 